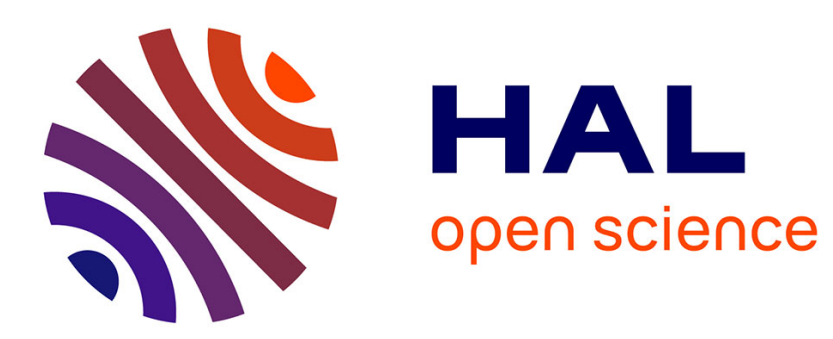

\title{
Current situation and perspectives in drug formulation by using supercritical fluid technology
}

Elisabeth Badens, Yasmine Masmoudi, Adil Mouahid, Christelle Crampon

\section{To cite this version:}

Elisabeth Badens, Yasmine Masmoudi, Adil Mouahid, Christelle Crampon. Current situation and perspectives in drug formulation by using supercritical fluid technology. Journal of Supercritical Fluids, 2018, 134, pp.274-283. 10.1016/j.supflu.2017.12.038 . hal-02111546

\section{HAL Id: hal-02111546 \\ https://hal-amu.archives-ouvertes.fr/hal-02111546}

Submitted on 26 Apr 2019

HAL is a multi-disciplinary open access archive for the deposit and dissemination of scientific research documents, whether they are published or not. The documents may come from teaching and research institutions in France or abroad, or from public or private research centers.
L'archive ouverte pluridisciplinaire HAL, est destinée au dépôt et à la diffusion de documents scientifiques de niveau recherche, publiés ou non, émanant des établissements d'enseignement et de recherche français ou étrangers, des laboratoires publics ou privés. 
archives-ouvertes

\section{Current situation and perspectives in drug formulation by using supercritical fluid technology}

Elisabeth Badens, Yasmine Masmoudi, Adil Mouahid, Christelle Crampon

\section{To cite this version:}

Elisabeth Badens, Yasmine Masmoudi, Adil Mouahid, Christelle Crampon. Current situation and perspectives in drug formulation by using supercritical fluid technology. The Journal of Supercritical Fluids, 2018, 134, pp.274-283. 10.1016/j.supflu.2017.12.038 . hal-02111546

\section{HAL Id: hal-02111546 \\ https://hal-amu.archives-ouvertes.fr/hal-02111546}

Submitted on 26 Apr 2019

HAL is a multi-disciplinary open access archive for the deposit and dissemination of scientific research documents, whether they are published or not. The documents may come from teaching and research institutions in France or abroad, or from public or private research centers.
L'archive ouverte pluridisciplinaire HAL, est destinée au dépôt et à la diffusion de documents scientifiques de niveau recherche, publiés ou non, émanant des établissements d'enseignement et de recherche français ou étrangers, des laboratoires publics ou privés. 


\title{
Current situation and perspectives in drug formulation by using supercritical fluid technology
}

\author{
Elisabeth Badens*, Yasmine Masmoudi, Adil Mouahid, Christelle Crampon \\ Aix Marseille Univ, CNRS, Centrale Marseille, M2P2, Marseille, France
}

\section{A R T I C L E I N F O}

Keywords:

Supercritical $\mathrm{CO}_{2}$

Drug formulation

Sustained release drug delivery systems

Crystallization

Particle generation

\begin{abstract}
A B S T R A C T
Supercritical fluid (SCF) technology has been applied to drug product development over the last thirty years and drug particle generation using SCFs appears to be an efficient way to carry out drug formulation which will form end-products meeting targeted specifications. This article presents an overview of drug particle design using SCFs from a rather different perspective than usual, more focused on chemical and process engineering aspects. The main types of existing processes are described in a concise way and a focus is put on how to choose the right operating conditions considering both thermodynamic and hydrodynamic aspects. It is shown that the operating conditions and parameters can be easily optimized so as to facilitate the further process scale-up. Furthermore, the new trends in particle generation using SCFs are introduced, related either to new types of drug medicines that are treated or new ways of process implementation methods.
\end{abstract}

\section{Introduction}

The main aim of drug formulation is to fulfil end-product specifications with regard to drug bioavailability, non-toxicity, uniformity, stability and handling properties. It is possible to enhance drug bioavailability, while meeting given specifications, either by micronizing the pure Active Pharmaceutical Ingredient (API), by modifying the crystal characteristics (habit and/or polymorphic nature), or by forming composite particles. Composite particles used as controlled or sustained release drug delivery systems can be matrix carriers, such as polymer-based or silica-based particles, or soft matter vesicular carrier as liposomes. The release of the drug can be accelerated or slowed down according to the nature of the excipient, thus allowing an optimization of the quantity of administrated drug, an increase in the benefit/risk ratio of the drug and better patient compliance.

Supercritical fluid (SCF) technology has been applied to drug formulation for the past 30 years and is now acknowledged as being a real alternative to conventional techniques using liquid organic solvents. Depending on the system under study, it is possible to either completely avoid the use of organic solvents, or, when their use is unavoidable, significantly reduce their quantity compared to many industrial processes. For these reasons, among others, it is generally accepted that processes using SCFs are environmentally friendly. In addition, the resulting end-products contain few to no traces of residual organic solvent.

More than a hundred APIs and a large number of excipients have been processed, using supercritical carbon dioxide $\left(\mathrm{SC} \mathrm{CO}_{2}\right)$ for the vast majority of cases [1-5]. One of the most interesting properties of $\mathrm{CO}_{2}$ for such applications is its low critical temperature $(\mathrm{Tc}=304.21 \mathrm{~K})$ and its easily-accessible critical pressure $(\mathrm{Pc}=7.38 \mathrm{MPa})$. This is a real advantage as a large number of pharmaceuticals are thermosensitive.

Another benefit of using $\mathrm{SC} \mathrm{CO}_{2}$ is that carbon dioxide is gaseous under ambient conditions of pressure and temperature, thus enabling the end-product to be separated spontaneously from $\mathrm{CO}_{2}$ simply by depressurizing. This means that $\mathrm{SC} \mathrm{CO}_{2}$ processes require a reduced number of unit operations compared to conventional methods which need several successive steps of drying and separating in order to recover a solvent-free end-product. Needless to say, a process requiring a reduced number of steps has the added advantage of forming products with homogeneous characteristics as there are fewer stages at which the properties of the product may evolve. For instance, in a multi-step crystallization process, the resulting crystals may evolve during the successive steps, thus exhibiting different characteristics in terms of size, particle size distribution, habit or polymorphic nature.

Furthermore, one is more likely to accurately control product characteristics using SCFs because of the large number of operating parameters and conditions (pressure, temperature, nature of the phases in presence, compositions, flow rates, introduction modes, mixing conditions,...) which can be varied in order to obtain an end-product with specific properties. Polymorphic screening, for example, may be more successful with SCFs than with conventional methods.

At the same time, over the past 20 years, an alternative to

\footnotetext{
* Corresponding author.

E-mail address: elisabeth.badens@univ-amu.fr (E. Badens).
} 
conventional medicinal therapy using anti-inflammatory drugs, glucocorticoids or immunosuppressants which can cause immediate or delayed adverse effects, has emerged. The strategy of this alternative therapy, which is also used for the treatment of genetic diseases, consists in using small molecules of RiboNucleicAcids (RNAs) to modulate endogenous gene expression. These small RNAs could constitute an innovative therapeutic solution for a large number of diseases. However, it is necessary to elaborate RNA formulations adapted to this molecule, the downside being that a non-protected strand of RNA will degrade rapidly in vivo under the action of endogenous ribonucleases or due to $\mathrm{pH}$ variations. Moreover, it is possible that a treatment using interferent RNAs could induce immune responses or cause adverse ef-fects. In order to circumvent these problems, it is possible to en-capsulate or trap the RNA molecule thus ensuring its protection once absorbed and linking it to the vector agent transporting it to the target organ. For about fifteen years, different types of RNA formulations have been elaborated using conventional methods [6] but also using SCFs [7-9] and their efficiency has been studied in vitro and in vivo.

There are two main SCF processes for elaborating controlled or sustained release drug delivery systems: i) particle generation processes, which use the SCF as a solvent, an anti-solvent or a dispersing agent; ii) impregnation processes for which the SCF is the impregnation agent/solvent. As in some particle generation processes, there is a solubilization step of the drug in the SC phase during the impregnation process. Hence, this drug solubilization can only be achieved for certain conditions of chemical affinity with the SC phase and of molecular size. Supercritical drug impregnation has been successfully applied over the last years to different types of supports, mainly "non-swellable" materials like silicas or "swellable" matrices like polymers. This technic is suitable for a drug amorphization [10]. The current new trend for SC impregnation is to impregnate medical devices [11] since it is possible to perform a homogeneous drug impregnation without modifying the properties of the impregnated support [12]. Supercritical drug impregnation will not be addressed in this paper which is dedicated to particle generation processes.

This article aims to lay out the current situation for the various processes of drug particle generation using SCFs hence guiding the reader in his or her choice to find the right process according to both the nature of the drug solute and the end-product or application de-sired. The different processes for the elaboration of controlled or sus-tained release drug delivery systems will be described in a concise and comparative way. The main issues linked to industrial scale-up will also be highlighted, taking into account that this scale-up will be easier once the different process steps are better controlled. This will be achievable after obtaining more thermodynamic data and knowledge about the transfer phenomena involved in the different processes. These aspects need to be addressed so as to fill the gaps in the knowledge about these technologies.

Lastly, novel views, mainly directed towards process intensification and process coupling will be outlined.

\section{Current state of particle generation processes}

These processes are applied either to the pure drug with the objective of micronization or modification of crystal morphology, habit or polymorphic form or to the drug in presence of one or more excipients for the purpose of slowing down or enhancing the drug release, of protecting/stabilizing the drug during storage or in the human body after its administration, of masking a bad taste, etc.

Processes of particle generation are almost always classified according to the role played by the supercritical fluid, acting as a solvent of precipitation, as an anti-solvent or as a dispersing agent. For greater clarity, this classification will be followed here and in addition, the different processes will be detailed from a chemical engineering angle. In particular, for each type of process, it will be discussed how better to control the end-product characteristics by choosing the right operating conditions. This is possible by considering both thermodynamic and hydrodynamic aspects. In recent years, many works have demonstrated that either experimental or modeling tools allow a deeper comprehension and mastering of the processes. We will detail here the main items to be considered for the three process types.

\subsection{SCF used as precipitation solvent}

When the SCF is used as a solvent, the process implies a first step of drug solubilization in the SC phase followed by an expansion of the resulting solution in a lower pressure vessel. The dramatic decrease in the solvent power during depressurization leads to high solute supersaturations and the formation of ultrafine particles. The most commonly used process using SCF as solvent is the Rapid Expansion of a Supercritical Solution (RESS) process.

This process is suitable for solutes having a solubility higher than about $10^{-3} \mathrm{~g} \mathrm{~g}^{-1}$ of SCF. The drug solubilization is carried out in a high-pressure cell (often called extraction or saturation vessel) swept by a continuous SCF flow rate. Depending on this flow rate and on the system studied, the concentration of the solute in the SCF reaches the solubility value. If the SCF-rich phase is saturated, the resulting supersaturation achieved during depressurization will be higher, the overall SCF consumption lower and the process productivity enhanced. The conditions of pressure and temperature (in the saturation and in the expansion vessels), the SCF flow rate as well as the geometry and diameter of the expansion nozzle/tube thus have to be carefully chosen.

Regarding the precipitation phenomenon during the RESS process, it occurs in a transitory regime. Pressure, temperature, composition/ supersaturation vary during the expansion of the SC solution; the latter occuring through capillary tubes or nozzles (with an internal diameter of a few tens of microns) at supersonic jet velocities according to the different cases, leading to high nucleation frequency. Crystallization characteristic times are commonly lower than $10^{-5} \mathrm{~s}$. A thorough understanding of the different mechanims involved in this rapid precipitation/crystallization is thus difficult.

Nevertheless, a large number of molecules have been micronized using the RESS process, most of them are small molecules, as for example acetylsalicylic acid, artemisinin, aspirin, $\beta$-carotene, $\beta$-estradiol, $\beta$-sisosterol, caffeine, carbamazepine, cyclosporine, fenofibrate, flavone, griseofulvin, ibuprofen, lazaroid, lidocaine, loperamide, medroxyprogesterone acetate, salicylic acid, taxol or testerone. A number of polymeric excipients have also been treated by RESS. We can enumerate the following:

\section{- polyhydroxic acids (polylactic acids-L-PLA and D,L-PLA, polyglycolic acid-PGA),}

- polyacrylates polymethyl of methacrylate - PMMA, PMMA-co-poly (glycidyl methacrylate), Poly(2-ethylhexyl acrylate), Poly(heptadecafluorodecyl acrylate),

- polyenes and polyvinyls Polyethylen Glycol - PEG, Polypropylen, PEG- polypropylen glycol, poloxamers, ethylen-buten copolymers, Polystyren, Ether de Poly(oxyalkylene) alkylphenyl ether, Polyvinylpyrrolidone - PVP, fluorure of Polyvinyliden, Poly(vinyl chlorure-co-vinyl acetate),

- cellulosic derivates (hydroxypropyl of cellulose, ethyl cellulose, triacetate of cellulose),

- other polymers (Hyaluronan-based polymer as HYAFF-11, Poly(dimethylsiloxane), bisphenol epoxy resin, perfluoro polyether).

When carbon dioxide is used as SCF, since it is apolar, the RESS process is more adapted to non-polar molecules eventhough the examples cited above show that polar molecules can also be reprecipitated by RESS process.

\subsubsection{Choice of operating conditions}

Pressure and temperature conditions in the saturation vessel are key 


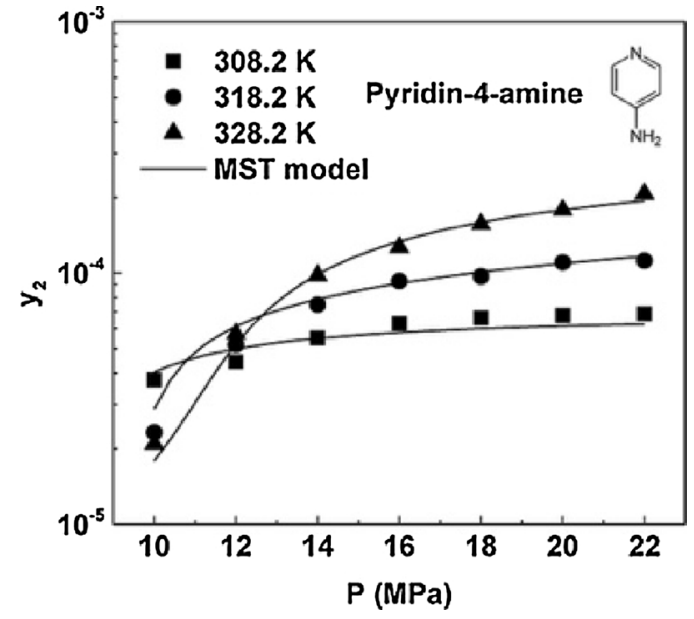

Fig. 1. Solubility of Pyridin-4-amine in $\mathrm{SC} \mathrm{CO}_{2}$ as a function of pressure and for different temperatures [13].

parameters that are chosen regarding the solute solubility in the SCF. It is recommended thus to evaluate its value as a function of pressure and temperature. As for example, the solubility of pyridin-4-amine was measured by Chen et al. [13] prior to RESS experiments. The values of the solubilities as a function of pressure and for different temperatures is reported in Fig. 1. These measurements enable the identification of the retrograde zone (below $12 \mathrm{MPa}$ ) where the solubility decreases when the temperature increases.

Fig. 1 Since a solute's solubility increases when pressure increases, the RESS process is often operated at pressure higher than $10 \mathrm{MPa}$. The operating conditions of pressure and temperature usually ranges between 10 and $40 \mathrm{MPa}$ and between 308 and $333 \mathrm{~K}$. A liquid co-solvent (generally from 1 to $5 \mathrm{wt} \%$ ) is sometimes used for increasing the solute solubility in the SC phase. In that case, the conditions of particle collection have to be well controlled in order to avoid the condensation of the co-solvent during depressurization. A solid co-solvent can also be used [14]; in that case the recovery of a dry end-product is easier.

Different works reported in literature over the last fifteen years have demonstrated that RESS-type processes can be very efficient for the coating of active pharmaceutical ingredients. Sub-micronic particles of flavone have been successfully coated by PEG at $308 \mathrm{~K}$ and $20 \mathrm{MPa}$ (Fig. 2a) [15]. It is worth noting that the RESS process can be ad-vantageously coupled with a fluidization bed allowing the coating of API particles. Schreiber et al. [16] obtained a homogeneous coating film of paraffin on the surface of lactose beads (Fig. 2b).

To conclude on RESS-type processes, it should be noted that the ratio $\mathrm{SCF} /$ solute is quite high (from 10 to $1000 \mathrm{~kg} \mathrm{~kg}^{-1}$ of solute) but this might not be an issue with the implementation of an efficient loop of SCF purification and recycling at larger scale. Besides the SCF management, the collection of the generated particles is a major concern. It implies collecting particles that are expected to be easily handled, without fine dust emissions and with a good flowability. One solution can be to trap the active principle solute in a fixed bed of excipient placed in the collection chamber. This approach was applied to the production of a powder constituted of sirolimus nanoparticles deposited on particles of microcrystalline cellulose [17]. Lastly, the enthalpy input during the fluid depressurization step is a major engineering difficulty. An intensive heating of the depressurization line is needed to avoid the $\mathrm{CO}_{2}$ condensation and an early solute precipitation. This is rather easy to implement at lab-scale but more difficult at larger scale. Innovative solutions have to be proposed for overcoming these issues.

\subsection{SCF used as precipitation anti-solvent}

When the SCF is used as an anti-solvent, the principle is the same as for conventional methods of recrystallization using a liquid anti-solvent. In that case, the solute to be precipitated is first solubilized in a liquid organic solution which is subsequently put into contact with the SCF. The organic solvent is chosen so as to be miscible in all proportions with the SCF. There are different processes using SCF as anti-solvent, they mainly differ from each other by the mode of introduction or the way of putting the two phases into contact. Among these different processes, the Supercritical Anti-Solvent (SAS) process is the most widely used.

When SC carbon dioxide is used, the SAS process is well adapted to most drug molecules which are often polar and may thus exhibit low solubility in $\mathrm{SC} \mathrm{CO}_{2}$. Over the last thirty years, dozens of drug solutes have been recrystallized pure or co-precipitated with excipients using SC anti-solvent techniques. As for examples, several works on acetaminophen, albumin, amoxicillin, ascorbic acid, aspirin, carbamazepine, cefuroxime, cholesterol, dexamethasone acetate, indomethacin, insulin and naproxen have been reported with or without excipients. All the polymeric excipients cited in the previous section have been used for SAS formulations.

A single vessel is used for the SAS process (Fig. 3), swept by a constant and continuous SCF flow rate. The solution containing the solubilized solutes (active pharmaceutical ingredients and excipients) is introduced in the high-pressure vessel through a capillary tube or nozzle (internal diameter varying from about $60-500 \mu \mathrm{m}$ ). The si-multaneous diffusion of the SCF in the liquid solution and of the organic solvent towards the continuous SC phase lead to the solute super-saturation and its crystallization/precipitation. The solid particles formed accumulate in the high-pressure cell and are collected after the depressurization. A well-known derivative of the SAS process is the Supercritical Enhanced Dispersion Solution (SEDS) process which uses a multichannel nozzle with a pre-mixing chamber for the introduction of the phases [1]. As represented in Fig. 3, the two phases can also be fed into the autoclave using impinging jets [18]. For both latter modes of introduction, mixing conditions are enhanced.
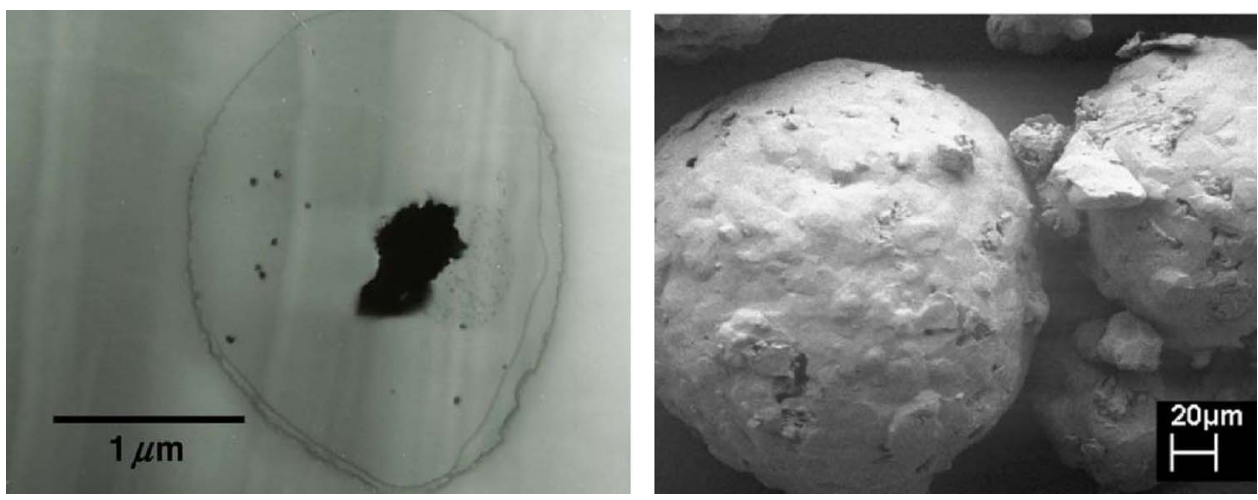

Fig. 2. (a) Flavone particles trapped in a polymeric matrix by a RESS-type process [15]. (b) Lactose beads coated by paraffin using RESS coupled with a fluidized bed [16]. 

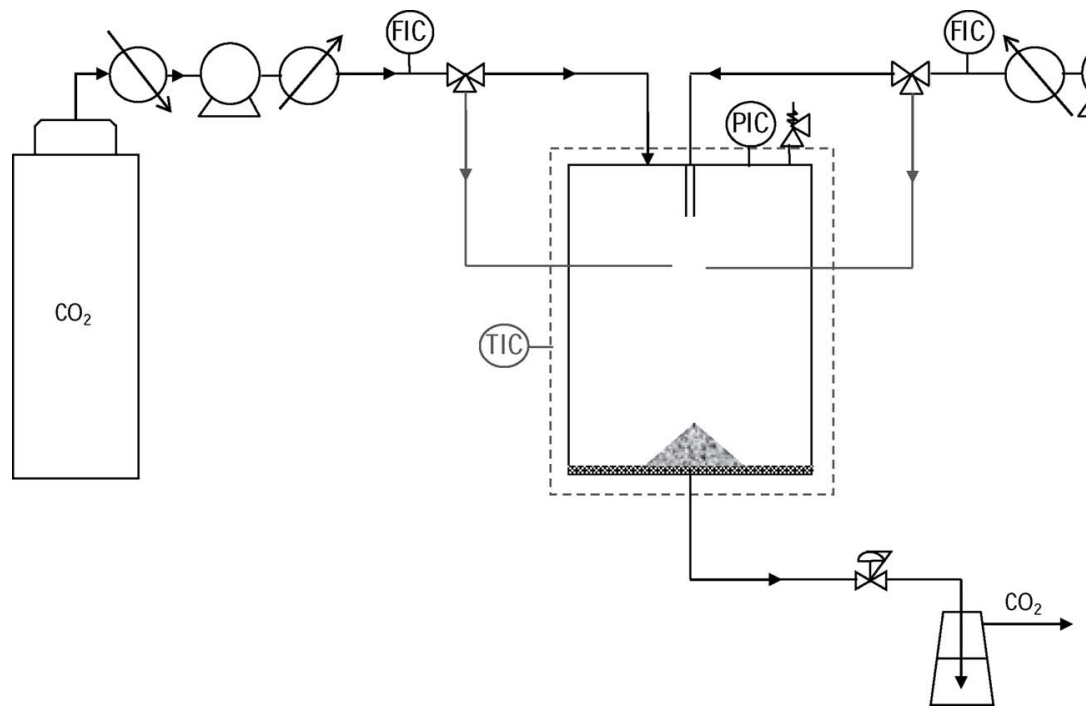

Fig. 3. SAS process flow diagram.

This process is of great interest since the crystallization occurs in steady state conditions: constant pressure, temperature, global fluid composition, flow rates.... As a consequence, the resulting particles may theoretically exhibit more homogeneous and repeatable characteristics than the ones obtained by processes involving a transient state crystallization. Moreover, such conditions of permanent regime are suitable for conducting fundamental studies (experimental or modeling ones) on the crystallization mechanisms, kinetic transfers and so on. The SAS process thus appears to be the most interesting process allowing a good control of the end-product characteristics. A drawback remains the use of an organic solvent but it has to be underlined that not only a nontoxic solvent as ethanol can be used but also edible or harmless compounds can play the role of solvent in the SAS process. For instance, the SAS process is used at an industrial scale for the produc-tion of micronized lecithin powder without the use of any organic solvent [19]. The mother solution is composed of phospholipids solu-bilized in a lipidic oil solution. The oil is soluble into $\mathrm{SC} \mathrm{CO}_{2}$ and this latter plays the role of anti-solvent for phospholipids which precipitate. Dry particles of lecithin can then be produced by SAS process at a production rate of 200 $\mathrm{kg} \mathrm{h}^{-1}$ without using any organic solvent.

Lastly, and still with regard to the use of organic solvents, some difficulties may occur at industrial scale to achieve a complete removal of residual solvent traces when low-volatile solvents are used, such as dimethyl sulfoxide or N-methyl pyrrolidone. It is thus recommended to use preferentially volatile solvents.

\subsubsection{Choice of operating parameters considering both thermodynamic and hydrodynamic aspects}

2.2.1.1. Choice of $P, T$ and global composition. Depending on the operating conditions in terms of pressure, temperature and composition, the nature of the phases in presence in the precipitation vessel will be different, leading to different conditions of mass transfer and phase flow. In a first attempt, the operating pressure and temperature can be chosen referring to the $\mathrm{CO}_{2}$-organic solvent binary diagram, $\mathrm{P}$-x. They are usually chosen so that the operating point is outside the biphasic envelope and for pressure and composition corresponding to a supercritical fluid phase, that is to say above the Mixture Critical Point (MCP). The MCP moves towards higher pressures and lower $\mathrm{CO}_{2}$ molar fraction when the temperature increases as it is illustrated in Fig. 4 for the binary system $\mathrm{CO}_{2}$-Methanol [20]. Since the presence of the solute has an impact on the phase behavior, the knowledge of the fluid phase equilibria of the ternary systems $\left(\mathrm{CO}_{2}\right.$-organic solvent-solute) may be helpful. Several hundreds of high pressure fluid phase equilibria for binary and ternary systems have been reported recently in the literature [21] and they are highly useful

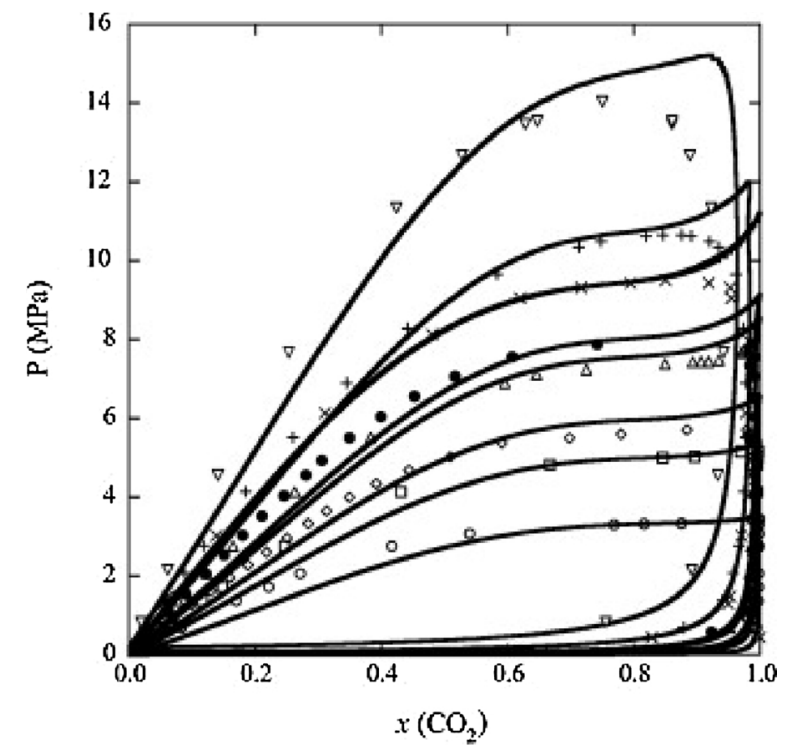

Fig. 4. P-x phase diagram of the $\mathrm{CO}_{2}+$ methanol at different temperatures. Solid lines correspond to SAFT-VR predictions using Lorentz-Berthelot combining rules, while symbols correspond to experimental data: $O, 273.15 \mathrm{~K} ; \square, 290.00 \mathrm{~K} ; \diamond, 298.15 \mathrm{~K} ; \Delta$, $310.00 \mathrm{~K} ; \cdot, 313.14 \mathrm{~K} ; \times, 323.20 \mathrm{~K} ;+, 330.00 \mathrm{~K} ; \nabla, 352.60 \mathrm{~K}[20]$.

for determining the right SAS process operating conditions.

2.2.1.2. Choice of flow rates. Once the pressure, temperature and global composition set, the flow rates of both the SCF and the organic solution have to be fixed. A given global composition can indeed correspond to different flow rates. The conditions of dispersion of the organic solution in the continuous supercritical one as well as the mixing conditions in the precipitation vessel have been studied by several authors $[18,22-$ 26]. For similar conditions of $P, T$ and global composition, it has been proved that the characteristics of the obtained powder are significantly influenced by the flow and mixing conditions.

As stated above, crystallization by the SAS process presents the advantage of occuring in a steady state regime, unlike RESS and PGSStype processes. In order to ensure these steady state conditons regarding the organic solvent/ $\mathrm{CO}_{2}$ ratio of the continuous fluid phase in the autoclave, it is necessary to introduce pure organic solvent prior to the introduction of the solution containing the solute to be precipitated. Indeed, to achieve a constant organic solvent $/ \mathrm{CO}_{2}$ ratio corresponding to the flow rate ratio of both phases, it is necessary to feed the autoclave 


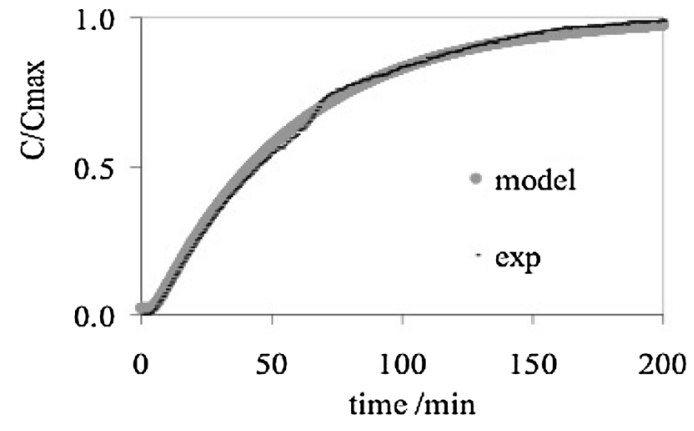

Fig. 5. Comparison between a well-mixed reactor model and an experimental RTD for a $1.5 \mathrm{~L}$ vessel at $8.6 \mathrm{MPa}, 313 \mathrm{~K}, \mathrm{CO}_{2}$ flow rate of $622 \mathrm{~g} \mathrm{~h}^{-1}$, liquid flow rate of $0.25 \mathrm{~mL} \mathrm{~min}$ -1 [22].

with pure solvent during a given duration. This duration can be estimated taking into consideration the macromixing in the autoclave. Carretier et al. [22,23] have characterized macromixing in the SAS precipitation vessel by determining the residence time distribution (RTD) using a tracing method. Step injections of toluene, used as a tracer in ethanol, were done simulating the organic solution injection during the precipitation step. The liquid injection was stopped and the evolution of solvent concentration into the precipitation vessel was recorded. In the experimental domain of operating conditions commonly used in the SAS process, the authors varied the flow rates of both liquid and $\mathrm{SC} \mathrm{CO}_{2}$ phases, the $\mathrm{CO}_{2}$ density as well as the geometry and volume of the autoclave. It has been shown that the precipitation vessel behaves like a well-mixed flow reactor whatever the conditions used as illustrated in Fig. 5 where the concentration $\mathrm{C}$ on the $\mathrm{y}$-axis corresponds to the tracer concentration in the outlet stream of the autoclave, measured using an online UV detector. The precipitation vessel is self-mixed by the injection of the two phases. The time required for achieving the targeted constant organic solvent/ $\mathrm{CO}_{2}$ ratio can then be estimated considering a well mixed flow reactor behavior. Once the steady state is achieved, the feed in the pure organic solvent is stopped and replaced by a feed with the organic solution containing the solute to be pre-cipitated.

In most cases, a capillary tube is used for the dispersion of the organic solution in the crystallization vessel. The organic solution flow rates usually used correspond to laminar flows which, depending on the operating conditions, lead to liquid jet atomization. Several authors have studied jet hydrodynamics in the SAS process and its influence on product characteristics. This is of great interest since it has been proved that for similar operating conditions in terms of $\mathrm{P}, \mathrm{T}$ and global composition, different hydrodynamic conditions lead to different properties of the end-product in terms of size, particle size distribution, polymorphic nature and so on. As recalled above, the macromixing was characterized for usual SAS conditions and the precipitation autoclave behaves like a well-mixed reactor during the introduction phase of the organic solution. It is then neceassry to go further in the hydrodynamics effects at a microscale as the micromixing and the jet dispersion modes can significantly influence the transfer phenomena during the crystallization.

The liquid laminar jet of the organic solution is then dispersed in the SC continuum through different dispersion modes depending on jet velocities: axisymmetrical, asymmetrical or atomized jet. Petit-Gas et al. [25] have shown that the critical atomization velocity is $0.38 \mathrm{~m} \mathrm{~s}^{-1}$ for different solvents and for usual SAS operating condi-tions. It thus appears that for the large majority of cases, the velocities used in the SAS process lead to jet atomization. If more efficient mixing conditions are expected, the jet velocity of the organic solution should be higher that this atomization threshold. The same authors visualized the jet dispersion in presence of the solute during the precipitation phase (Fig. 6). It is worth noting that for their studied sytem and op-erating conditons, the precipitation was initiated in the jet dispersion zone.

\subsubsection{Crystallization phase}

The duration of the crystallization phase is of great importance since the powder characteristics can evolve during this stage in the autoclave. The continuous phase (rich in $\mathrm{CO}_{2}$ ) contains organic solvent and the solubilized solute. Even for solutes presenting rather low solubilities in the SC phase, crystal evolution can be observed if the crystallization phase is long. Crystal growth can occur/continue and some variations in size, habit or even polymorphic transition may happen. Some authors have performed the recrystallization of sulfathiazole using the SAS process and have varied, among other parameters, the duration of the crystallization step from 3 to $8 \mathrm{~h}$ [27]. They have obtained different polymorphic forms depending on the duration. For instance, they obtained a pure polymorphic form (form IV) with a duration of $4 \mathrm{~h}$ while a mixture of two different polymorphic forms (forms IV and I) was obtained after $8 \mathrm{~h}$ of crystallization in similar conditions [27]. It is advisable to pay attention to the duration of the precipitation phase during the scale-up so as to avoid the formation of an unexpected form.

\subsubsection{Washing step}

Once the precipitation phase is finished, a washing step is required in order to avoid organic solvent condensation during depressurization and the presence of residual traces of organic solvent in the powder. This washing step is then conducted for renewing the fluid phase in the autoclave and consists in sweeping this latter with a pure $\mathrm{CO}_{2}$ flow. In order to optimize this phase, it is recommended to introduce the $\mathrm{CO}_{2}$ by the top of the autoclave. Indeed, since the pure $\mathrm{CO}_{2}$ is lighter than the binary fluid mixture $\mathrm{CO}_{2}$-organic solvent, the autoclave behaves like a plug flow reactor if $\mathrm{CO}_{2}$ is introduced by the top while it behaves like a well-mixed reactor if $\mathrm{CO}_{2}$ is introduced by the bottom. This has been established by RTD measurements conducted under classical SAS conditions. As illustrated in Fig. 7, a plug flow reactor behavior is preferred since it corresponds to lower required washing times to renew the content of the autoclave.

Once the washing step is finished, the precipitation vessel can be depressurized and the particles collected. This collection is easier for the SAS process than for RESS-type or PGSS-type processes since the particles have been accumulated in the high-pressure vessel and their recovery consists in emptying it. Nevertheless, since the particles are often fine ones, their collection requires adapted solutions. The different considerations are discussed in the section Challenges.

To illustrate the influence of operating process parameters upon the particle characteristics discussed above, we can cite the example of cefuroxime precipitated from DMSO solutions [28]. Varying the initial solute concentration, the authors observed different morphologies (see Fig. 8) and link it to the location of the process operating point in relation with the ternary system mixture critical point. The « wrinkled particles » were obtained for more concentrated solute solutions; these conditions may correspond to a precipitation in a subcritical gaseous phase.

In recent years, the SAS process has been proven to be highly efficient either for the micronization of pure drug or for encapsulation. It is worth mentioning here that cocrystals have also recently been formed by anti-solvent technics [29].

As for an example for successful encapsulation, stable formulations of quercetin have been elaborated using the SAS process [30]. Quercetin is an antioxidant exploited for pharmaceutical and cosmetic applications, thus presenting a high risk of oxidation and poor water solubility. Quercetin (Fig. 9a) was firstly micronized pure using ethyl acetate as a solvent at $10 \mathrm{MPa}$ and $308 \mathrm{~K}$. Submicronic crystals were obtained (Fig. 9b). In similar conditions and in presence of ethyl cellulose as excipient, solid dispersions of amorphous quercetin in ethyl cellulose were formed exhibiting an encapsulation efficiency up to $99 \%$ and with a process yield above $85 \%$ (Fig. 9c). The stability of coprecipitates were tested after one-year of storage; no reduction in 

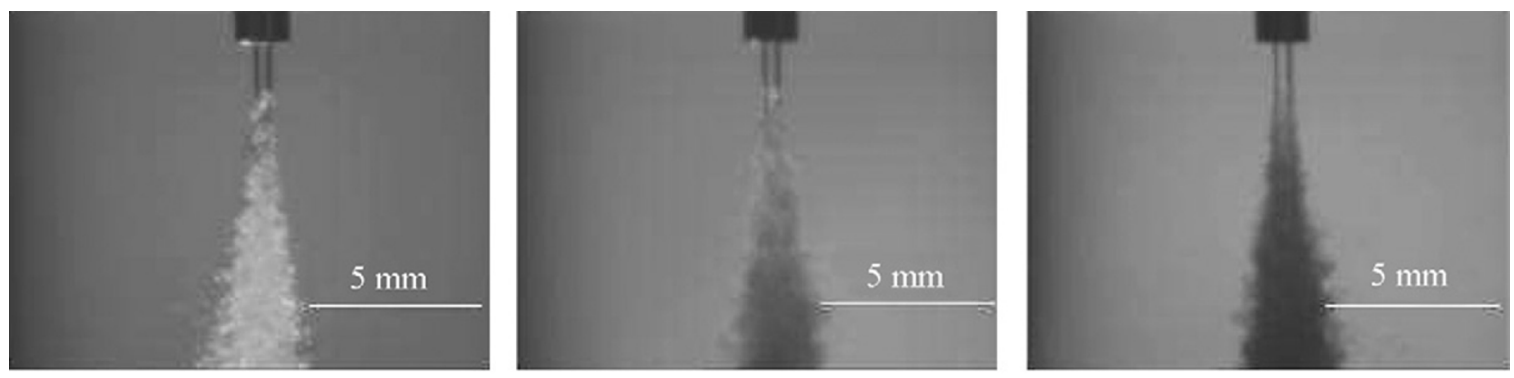

Time

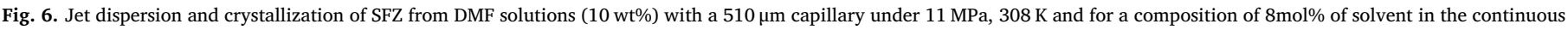
phase [24].

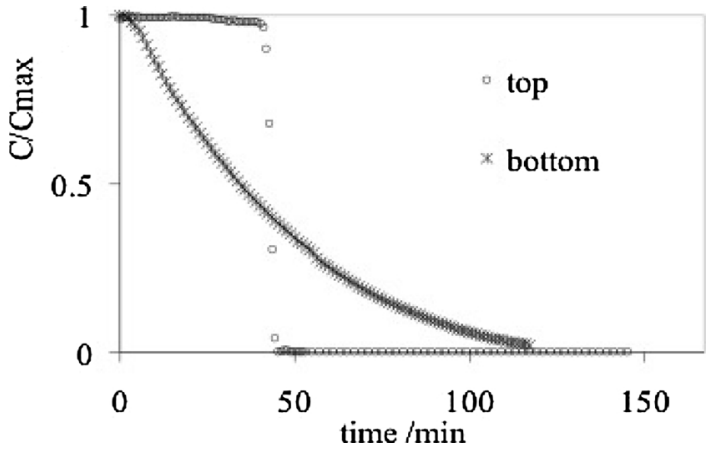

Fig. 7. Experimental RTD respectively related to the introduction of the antisolvent through the top or through the bottom of a $0.75 \mathrm{~L}$ vessel at $8.6 \mathrm{MPa}, 313 \mathrm{~K}, \mathrm{CO}_{2}$ flow rate of $622 \mathrm{~g} \mathrm{~h}$ ${ }^{-1}$ [22].

antioxidant activity was observed.

Another example of successful encapsulation but with lower drug loading and precipitation yield is that of a tuberculous drug, rifampicin [31]. Solid dispersions of rifampicin loaded in an ethyl cellulose matrix were obtained exhibiting a drug loading up to $38.5 \%$ and a drug precipitation yield up to $77.2 \%$.

SAS process has been recently coupled with a fluidized bed for elaborating innovative drug formulations [32]. Excipient particles (microcrystalline cellulose) have been fluidized under pressure and coated with amorphous nanoparticles of naringin, used as a poorly watersoluble model drug. Higher drug release rates have been mea-sured for the innovative SAS formulations in comparison with the ones obtained using conventional fluidized bed coating processes.

In addition to conventional drug molecule processing, anti-solvent processes appeared to be efficient for the elaboration of sustained re-lease drug delivery systems of biomolecules like proteins [33] or of larger biomolecules like nucleic acids [7-9,34]. These works have shown that processes using SCFs are suitable for the formulation of nucleic acid molecules that are rather fragile. It has been shown by

(a)

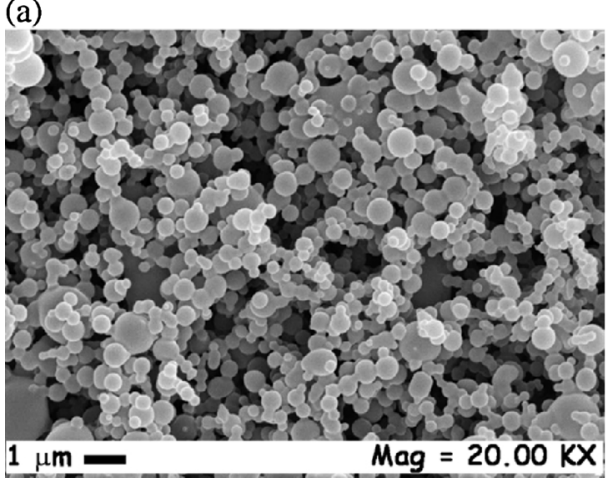

(b)

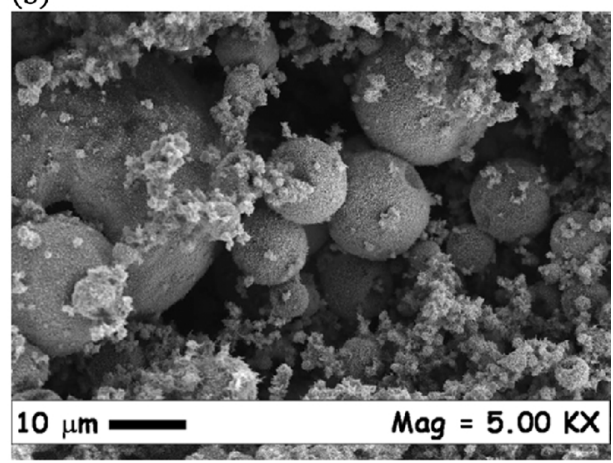

different authors that a particular attention has to be paid to the $\mathrm{pH}$ conditions.

In sum, it has been underlined that SAS-type processes enable a large number of active pharmaceutical ingredients to be treated. However, it should be pointed out that a significant number of APIs, especially biomolecules, are water soluble and in that case, SAS process operating conditions have to be adapted since water has a limited so-lubility in SC $\mathrm{CO}_{2}$. For such molecules, a first solution is to use a mix-ture of ethanol and water to solubilize the drug and choose the right operating conditions for complete water removal during the precipita-tion phase. Another alternative is to start from an aqueous solution of the active ingredient but to use a mixture of carbon dioxide and of organic solvents as supercritical fluids. Bovine serum albumin, initially solubilized in water has been micronized using carbon dioxide in mixture with ethanol, acetone or isopropyl alcohol [35]. Proteins have also been successfully precipitated from emulsions [36]. Microspheres of PLGA loaded with insulin have been elaborated by Supercritical Emulsion Extraction in a continuous mode and the drug release has been studied in myoblast culture [37].

It is also worth noting here that others compounds than $\mathrm{CO}_{2}$ can be used. As for an example, dimethyl ether (DME) is already accepted by several drug agencies as a "generally recognized as safe" (GRAS) solvent and appears to be efficient for drying biomolecules. DME is thus an interesting alternative to $\mathrm{CO}_{2}$ even if precautions must be taken to prevent explosion hazards.

Finally, the Supercritical Assisted Atomization (SAA) process broadens the scope of the SC anti-solvent techniques of particle generation, in particular, by allowing the treatment of aqueous phases. In this process, the solution containing the solute to be precipitated is saturated with $\mathrm{CO}_{2}$ in a packed mixing cell. This saturated solution is dispersed using an injection nozzle into a second cell in which the precipitation takes place. The atomization of the solution is assisted by a nitrogen flow at a higher temperature. The size of the formed particles varies from several dozens of nanometers to several hundreds of microns depending on the system studied and operating conditions. MMSO at $150 \mathrm{bar}, 313 \mathrm{~K}$;(a) sub-microparticles at $50 \mathrm{mg} \mathrm{mL}^{-1}$; (b) wrinkled microparticles and shells at $75 \mathrm{mg} \mathrm{mL}^{-1}$ [28]. 

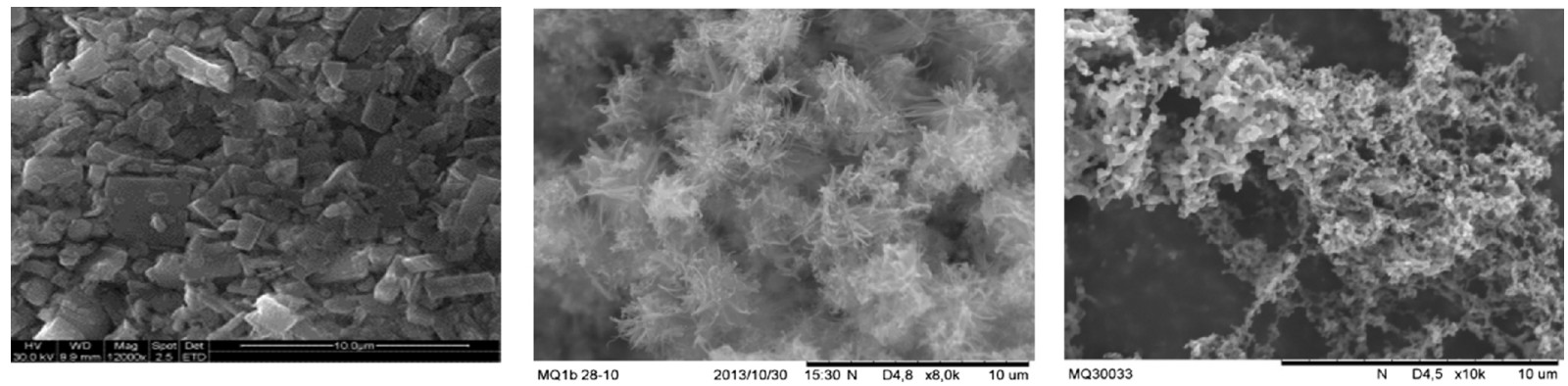

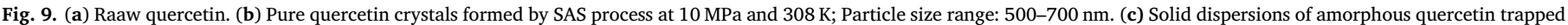
in ethyl cellulose, formed by SAS process at $10 \mathrm{MPa}$ and $308 \mathrm{~K}$; Particle size range: 150-350 nm [30].

Several drug molecules have been treated by this process [38]. The SAA process can lead to the formation of amorphous particles as well as crystalline, starting either from organic phases or aqueous phases.

\subsection{SCF used as dispersing agent}

Supercritical $\mathrm{CO}_{2}$ can be used as a dispersing agent when it presents a certain solubility in the compounds to be precipitated. $\mathrm{CO}_{2}$ solubilizes itself in the solutes and/or in the excipients brought to certain conditions of pressure and temperature so as to be molten. This type of process is particularly suitable for polymers in which $\mathrm{CO}_{2}$ is sorbed in significant quantities, resulting in their plasticization. In that case, unlike the other processes described above, the $\mathrm{CO}_{2}$ fraction (relative to the global composition) is much lower than in RESS or SAS-type processes. This first step of $\mathrm{CO}_{2}$ solubilization is carried out in a highpressure vessel often called mixing vessel where the active solute(s) and the excipient(s) have been initially placed (see Fig. 10). An adapted stirring device has to be used to ensure optimized mixing conditions. An anchor type or helicoidal agitation mobiles can be used since the molten mixtures are generally viscous. The molten mixture is expanded in a second vessel, often called collection or precipitation chamber, placed in lower pressure conditions. This expansion can either be car-ried out at ambient pressure or at a pressure higher than $\mathrm{CO}_{2}$ critical pressure [39]. The expansion is often assisted by a nitrogen or an air flow (or both) so as to help the $\mathrm{CO}_{2}$ release and the dispersion of the

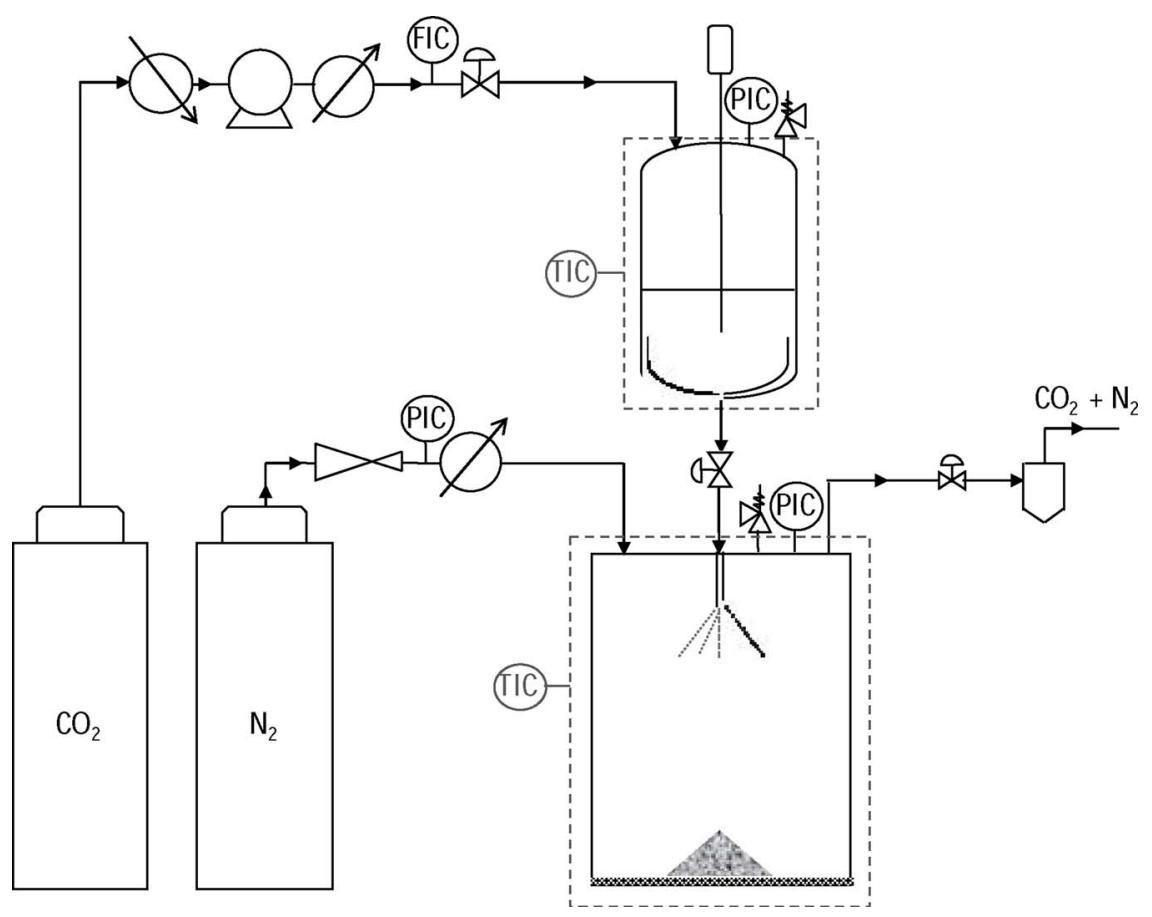

formed particles, limiting their coalescence or aggregation, as well as their retention on the vessel walls. Nitrogen or air are fed using individual feed lines or multichannel nozzles, also used for the expansion of the molten mixture. As for RESS process, the temperature of the mixing vessel, of the collection chamber and of the pre-expansion tubing have to be well-chosen and controlled.

In comparison with RESS and SAS-type processes, PGSS process has the main advantages of requiring a much smaller quantity of SCF (from about 1 to a few $\mathrm{g}$ of $\mathrm{CO}_{2}$ per $\mathrm{g}$ of solute) and of leading to high precipitation yieds (frequently $100 \%$ ). And contrary to the SAS process, the use of organic solvents is avoided. Despite these multiple benefits, as for RESS-type processes, some issues of tube clogging occuring during the expansion or difficulties for properly recovering the particles formed in an expansion stream are frequently reported. In addition, precipitation occurs during a depressurization phase, thus in transitory conditions. This make it more difficult to predict the end-product characteristics and to rationalize experimental results.

Nevertheless, the PGSS process is efficient for encapsulating biomolecules without any previous step of solubilization of the biomolecules either in an organic solvent or in $\mathrm{SC} \mathrm{CO}_{2}$. The plasticized polymer and a dry powder of the drug solute are mixed under pressure. The dry powder of the solute to be trapped can be ground in a preliminary step. Ribonuclease A, lysozyme and insulin were coprecipitated in poly(DLlactic acid) starting from suspensions of the proteins in the plasticized polymer excipient at $32 \mathrm{MPa}$ and $308 \mathrm{~K}$ [39]. The mixtures were further 
sprayed through a cone nozzle in a collecting chamber placed at lower pressure conditions ( $9 \mathrm{MPa}$ ) and filled with nitrogen. The recovered coprecipitates exhibited particle sizes ranging from 10 to $300 \mu \mathrm{m}$ depending on the operating conditions and solute nature.

Another type of drug, the human Growth Hormone-hGH, has also been succesfully coprecipitated by Jordan et al. [40] using the PGSS process in similar conditions to those mentioned above. Formulations of hGH (10 wt $\%$ ) in PLGA/PLA (80 wt $\%$ ) and in presence of other excipients $(10 \mathrm{wt} \%)$ were elaborated with a drug encapsulation efficiency of $100 \%$. The authors performed in vivo studies in rats and cynomolgus monkeys demonstrating that the obtained formulations allowed promising results to be obtained in terms of drug release kinetics, tolerance and inflammatory responses. It is worth noting that the stability of hGH in $\mathrm{SC} \mathrm{CO}_{2}$ was further studied [41], the conclusion being that the hGH structural integrity is unaffected by $\mathrm{SC}^{\mathrm{CO}_{2}}$ processing under the coprecipitation conditions of the PGSS-type process used.

Bovine Serum Albumin (BSA) has also been successfully coprecipitated by PGSS process [42]. Formulations of BSA (10 wt $\%$ ) in triblock copolymers (P(L)LA-PEG1.5 kDa-P(L)LA) used as excipients were elaborated. It was shown that the triblock molecular weight and the PEG/ PLA ratio influence both the particle size of the coprecipitates and the yield while no modification of the shape and of the protein encapsulation efficiency was observed.

The use of other types of excipients have also been reported in the literature for PGSS process applications. Ribonuclease A was coprecipitated by the PGSS process using lipidic compounds (tristearin and phosphatidylcholine) as excipients in addition to PEG [43]. The protein encapsulation was performed on both the native form and the PEGylated form. It was demonstrated that the PEGylation allows a protein integrity protection.

Lipidic compounds have also been used as sole excipients, without polymers, for encapsulating Curcumin using the PGSS process [44]. Micron-sized coprecipitates of curcumin in a matrix composed of tristearin and soy phosphatidylcholine were elaborated with a drug loading varying from 30 to $87 \mathrm{wt} \%$. It should be noted that in that case, it was not a solvent-free process since the curcurmin was initially in solution in DMSO. As for previous works reported in literature, flows of nitrogen and air have been used to assist the spraying of the mixture in the collection chamber and to optimize thier collection.

An innovative modified PGSS process was used by Couto et al. [45] to elaborate solid lipidic particle encapsulates of a bioactive compound, Vitamin B2. The molten mixture composed of fully hydrogenated canola oil, vitamin B2 and a surfactant (sodium lauryl sulfate) was expanded in a water stream containing PEG used as stabilizer. Aqueous suspensions of lipidic nanoparticles encapsulating Vitamin B2 were obtained. The authors have discussed the influence of the variation of pressure (from 10 to $25 \mathrm{MPa}$ ), active solute and surfactant concentrations and of stabilizer MW upon the encapsulation efficiency, bioactive load and particle size. For example, the encapsulation efficiency varied from 12 up to $48 \%$ and the bioactive loads from 0.09 up to $0.73 \mathrm{mg} \mathrm{g}^{-1}$. It is worth noting that a lower pressure led to the formation of larger particles with higher encapsulation efficiency and active loading. Besides, higher active solute concentrations resulted in larger particles and higher encapsulation efficiency as well as active loads.

In addition, it is worth noting that completely different natures of compounds, such as virus [46] and bacteria [47], have been coprecipitated by the PGSS process.

Lastly, it should be pointed out that the plasticization of polymers using $\mathrm{SC} \mathrm{CO}_{2}$ is also exploited in another type of process involving extruders [48].

\section{Challenges}

As seen above, SCF processes applied to drug formulation have been studied in a rather sustained manner for about thirty years. It is worth noting that SCF technology for drug formulation emerged in the industry twenty years ago but has been very slow to be implemented. The scale-up is still a real challenge to be overcome for a rather large number of cases but much progress has been achieved in recent years.

\subsection{Particle collection}

As already mentioned above and regardless of the process used, the recovery of the nano- or microparticles is not always easy to manage. The conditions of particle collection have to meet the Good Manufacturing Practices (GMP) guidelines and ensure good efficiency. A filtration bag can be used to collect particles in the precipitation chamber. For RESS-type and PGSS-type processes, the particles are collected from a fluid current. Several methods may be used: particle collection by inertial effect (cyclones, impact chambers,...), by electrostatic effect, by washing with liquids or by filtration through a porous medium, the last two methods being appropriate for the col-lection of ultrafine particles. The particles can also be trapped in a solid powder, for example dry ice, or as previously mentioned in a bed of excipient [17].

Lastly, to turn a batch process into a semi-batch process, at least two collection cells can be used and fed alternatively by the current of fluid charged with particles. For the SAS-type process, an additional collection cell can be used for recovering the powder, turning the semi-continuous process into a continuous one.

\subsection{Residual solvent content}

Anti-solvent processes imply the use of an organic solvent that may remain present as residual traces in the end-product. It has been seen in Section 2.1.2 that the washing step with pure $\mathrm{CO}_{2}$, subsequently to the precipitation step is performed not only to renew the fluid content of the autoclave and avoid the solvent condensation during depressur-ization but also to completely eliminate solvent traces. It is worth noting that the powder is required to be evenly distributed in the pre-cipitation cell so as to avoid $\mathrm{CO}_{2}$ flowing in preferential paths, thus resulting in a less efficient washing and in the formation of particle aggregates. This may happen at larger scale. One solution is to alternate washing with a SCF flow through the top and bottom of the cell con-taining the powder.

\subsection{SCF consumption, purification and recycling}

It has been seen that depending on the process considered, the SCF/ solute ratio is different and varies from about 1 to up to $10000 \mathrm{~kg} \mathrm{~kg}^{-1}$ of solute (at lab-scale). This SCF/solute ratio can be reduced during the change of scale and a maximum value of $50 \mathrm{~kg} \mathrm{~kg}^{-1}$ of solute is preferentially targeted at industrial scale. This ratio has an impact on the implementation of the recycling and on the choice of the equipment which is dependent on the required fluid flows.

Thus, the fluid recycling implementation will depend on the process considered. When the SCF/solute ratio is low $(\approx 1)$, which could be the case for PGSS-type processes, the SCF cannot be recycled. For higher ratios, especially for SAS-type and RESS-type processes, the fluid must be recycled. Recycling is also necessary when the SCF used is a fluid with toxic and/or security problems such as dimethyl ether or propane. Two criteria are considered for the SCF recycling: the quantity of the fluid to be recycled and the fluid recompression. Up to $98 \%$ of the SCF can be recycled.

Regarding the purification of the SCF during the recycling, a step of separation of the SCF and the organic solvent or solute has to be considered, especially when the recycling of the fluid takes place at a pressure around $5 \mathrm{MPa}$. The adsorption of the solvent or the solute on an activated carbon bed is efficient in numerous cases. 


\section{Knowledge Gaps/Needs}

Whatever the process consid a better control of product characteristics implies more knowledge in terms of thermodynamics and hydrodynamics.

Concerning thermodynamics aspects, a first requirement is to evaluate the nature of the phases in presence for a given system depending on the conditions of pressure and temperature. The transfer kinetics will depend on this. A large number of high-pressure fluid phase equilibria for binary systems involving carbon dioxide and or-ganic solvents, as well as ternary systems involving $\mathrm{CO}_{2}$, an organic and a solute are now available in literature [21,49]. Nevertheless, there is not enough data as not all the pressure and temperature ranges usually used for particle generation are covered. There is a real need of ex-perimental data measurements of high pressure fluid phase equilibria involving solutes.

A wide number of works of modeling of high-pressure fluid phase equilibria are reported in literature. For the vast majority of them, the models used are not predictive and thus require experimental data. A step forward would be made if reliable models were developed for the prediction of high-pressure fluid phase equilibria involving carbon dioxide, organic solvent and solutes of interest for pharmaceuticals. The knowledge of these phase equilibria will allow the further study of transfer kinetics but it is also helpful for the estimation of solute solubilities [50]. The knowledge of solubilities enables the right operating conditions to be chosen in terms of pressure, temperature and global composition during the implementation of the processes. This knowledge also allows the further estimation of the supersaturations involved during the precipitation phase.

When the crystallization is conducted with the purpose of controlling the crystal polymorphic form, this would be easier if the solute polymorph phase diagram were known not only at ambient pressure but also for high pressure. When a solute presents different poly-morphic forms, for the ones presenting enantiomeric systems, the most stable form at ambient pressure may not be the most stable at high pressure [1]. Thus, a full understanding of the phenomena involved during crystallization using SCF may imply a complete knowledge of phase equilibria.

Since a large number of polymeric excipients are used, more studies on the modification of polymer properties in presence of dense $\mathrm{CO}_{2}$ are required. The characterization of the polymer plasticization helps the choice of the right operating conditions for a given process. Data such as $\mathrm{CO}_{2}$ uptake, glass transition temperature depression, polymer swel-ling and so on are of great interest for a good control of polymer pro-cessing. Several works have already been reported on these topics [51-55] but more data on all the different systems used for drug for-mulation are needed.

There is also a knowledge gap concerning the phenomena of nucleation and growth in supercritical media. No fundamental studies have been dedicated to the influence of the specific properties of SCF on the nucleation frequencies and growth kinetics, considering the usual operating conditions of drug particle generation.

Lastly, it has to be highlighted that several works of in situ measurements have been reported over the last decade contributing to filling the gaps [56-58]. Indeed, different methods such as in situ FTIR measurements or in situ laser scattering allow a deeper study of polymer swelling or $\mathrm{CO}_{2}$ uptake, and in a more general way a study of the different interactions between the drug solutes, polymers and $\mathrm{SC} \mathrm{CO}_{2}$. These techniques will then enable useful information to be provided about transfer phenomena involved in the processes of particle generation using SCF.

\section{Future Directions/Perspectives}

Now that these different drug particle generation processes have been mastered, it is of interest to explore a coupling with conventional methods or with other processes using SCF. For example, supercritical extraction of a compound of interest from a dry natural product can be easily coupled with a particle generation process that could be implemented subsequently to extraction, in a separation vessel. Integrated process can thus be implemented, avoiding or limiting the use of organic solvent and allowing a good control of the end-product characteristics.

Another application of SC $\mathrm{CO}_{2}$ currently studied, either at lab-scale or for industrial applications, is $\mathrm{SC} \mathrm{CO}_{2}$ sterilization. Indeed, depending on operating conditions, $\mathrm{SC} \mathrm{CO}_{2}$ allows complete inactivation or at least significant bioburden reduction [59]. It is thus worth noting here, that the conditions used for particle generation may correspond to conditions ensuring a significant bioburden reduction, with an efficiency that will depend (in addition to the operating conditions) on the initial bioburden and the type of contamination. It is then of great interest to exploit this specific property of $\mathrm{SC}_{\mathrm{CO}_{2}}$.

Furthermore, as a general rule, the current trend in the industry is to focus on optimization and intensification aspects. In the particular case of supercritical technology, this approach can provide a solution for reducing energy consumption. Other advantages like the reduction of the unit's size and thus of the space occupied by the facilities, the decrease of the production costs and in addition a higher security of the plants are also strengths of these methods. The development in recent years of supercritical microfluidic equipment applied to different SCF applications will allow progress in this path [60]. The currently progressing modeling approaches applied to these specific media $[61,62]$ will allow a better control of the processes in general and of the intensification in particular. All the different phenomena that have to be further studied for a better control of the different processes will then also have to be tackled at this lower scale.

As concerns the development of the SCF technology in the pharmaceutical industry, it is still in the early stages. Although particle generation processes using SCFs have been widely studied over the last three decades, there are only a few industrial units. Several reasons can be given to explain this. First of all, the processes described have not all been mature for a long time. Several scale-up issues have been the consequences of an improper choice of operating conditions at industrial scale. For example, as previously mentioned, the duration of the precipitation step for anti-solvent processes is of great importance. Endproducts with different characteristics are obtained if the pre-cipitation step durations are not the same at lab-scale and at industrial scale. The different particle design processes using SCFs are now much more mature and useful results are now available for more reliable scale-ups. Furthermore, some economic data are now available in the literature [63]. A second reason may be that the products elaborated using these processes did not all fit a market. Indeed, the market for products elaborated using environmentally friendly processes is rather recent. Moreover, the majority of current legislation all over the world still allows the use of conventional liquid organic solvents.

Lastly, an important change in recent years is that several companies used as service providers can now ensure the scale-up study, the production of clinical batches (required for clinical studies) and even the production of commercial batches. This allows a product development without necessarily requiring investment costs. For all these reasons and because SCF technology can be considered as environmentally friendly, it seems inevitable that its development will grow in the pharmaceutical industry in the near future.

\section{References}

[1] P. York, U.B. Kompella, B.Y. Shekunov, Supercritical Fluid Technology for Drug Product Development, Drugs Pharm. Sci. 18 Marcel Dekker, New-York, 2004.

[2] J. Fages, H. Lochard, J.J. Letourneau, M. Sauceau, E. Rodier, Particle generation for pharmaceutical applications using supercritical fluid technology, Powder Technol. 141 (2004) 219-226.

[3] E. Badens, Supercritical Fluid Technology in Pharmaceuticals, Les Techniques de l'Ingénieur, CHV4010en, (2012). 
[4] P.J. Ginty, M.J. Whitaker, K.M. Shakesheff, S.M. Howdle, Drug delivery goes supercritical, Nanotoday 8 (2005) 42-48.

[5] I. Pasquali, R. Bettini, Are pharmaceutics really going supercritical? Int. J. Pharmaceut. 364 (2008) 176-187.

[6] J. Guo, X. Jiang, S. Gui, RNA interference-based nanosystems for inflammatory bowel disease therapy, Int. J. Nanomed. 11 (2016) 5287-5310.

[7] G.B. Jacobson, E. Gonzalez-Gonzalez, R. Spitler, R. Shinde, D. Leake, R.L. Kaspar, C.H. Contag, R.N. Zare, Biodegradable nanoparticles with sustained release of functional siRNA in skin, J. Pharm. Sci. 99 (2010) 4261-4266.

[8] J. Ge, G.B. Jacobson, T. Lobovkina, K. Holmberg, R.N. Zare, Sustained release of nucleic acids from polymeric nanoparticles using microemulsion precipitation in supercritical carbon dioxide, Chem. Commun. 46 (2010) 9034-9036.

[9] T. Okuda, D. Kito, A. Oiwa, M. Fukushima, D. Hira, H. Okamoto, Gene silencing in a mouse lung metastasis model by an inhalable dry small interfering RNA powder prepared using the supercritical carbon dioxide technique, Biol. Pharm. Bull. 36 (2013) 1183-1191.

[10] P. Gurikov, I. Smirnova, Amorphization of drugs by adsorptive precipitation from supercritical solutions: a review, J. Supercrit. Fluids 132 (2018) 105-125.

[11] M. Champeau, J.M. Thomassin, T. Tassaing, C. Jérôme, Drug loading of polymer implants by supercritical $\mathrm{CO}_{2}$ assisted impregnation: a review, J. Controlled Release 209 (2015) 248-259.

[12] A. Bouledjouidja, Y. Masmoudi, Y. Li, W. He, E. Badens, Supercritical impregnation and optical characterization of loaded foldable intraocular lenses using supercritical fluids, J. Cataract. Refr. Surg. 43 (2017) 1343-1349.

[13] C.T. Chen, C.A. Lee, M. Tang, Y.P. Chen, Experimental investigation for the solubility and micronization of pyridin-4-amine in supercritical carbon dioxide, J. $\mathrm{CO}_{2}$ Util. 18 (2017) 173-180.

[14] R. Thakur, R.B. Gupta, Formation of phenytoin nanoparticles using rapid expansion of supercritical solution with solid cosolvent (RESS-SC) process, Int. J. Pharm. 308 (2006) 190-199.

[15] K. Matsuyama, K. Mishima, K.I. Hayashi, H. Ishikawa, H. Matsuyama, T. Harada, Formation of microcapsules of medicines by the rapid expansion of a supercritical solution with a nonsolvent, J. Appl. Polym. Sci. 89 (2003) 742-752.

[16] R. Schreiber, B. Reinke, C. Vogt, J. Werther, G. Brunner, High-pressure fluidized bed coating utilizing supercritical carbon dioxide, Powder Technol. 138 (2003) 31-38.

[17] F. Leboeuf, C. Herry, J. Jung, F. Deschamps, Sirolimus nanoparticles tablets, 2nd Conference Innovation in Drug Delivery, 3-6 October, Aix-en-Provence, France, 2010, p. 106.

[18] S. Careno, O. Boutin, E. Badens, Drug recrystallization using Supercritical AntiSolvent (SAS) process with impinging jets: effect of process parameters, J. Cryst. Growth 342 (2012) 34-41.

[19] E. Weidner, High pressure micronization for food applications, J. Supercrit. Fluids 47 (2009) 556-565.

[20] K. Tochigi, T. Namae, T. Suga, H. Matsuda, K. Kurihara, M.C. dos Ramos, C. McCabe, Measurement and prediction of high-pressure vapor-liquid equilibria for binary mixtures of carbon dioxide + n-octane, methanol, ethanol, and perfluorohexane, J. Supercrit. Fluids 55 (2010) 682-689.

[21] J.M.S. Fonseca, R. Dohrn, S. Peper, High-pressure fluid-phase equilibria: experimental methods and systems investigated (2005-2008), Fluid Phase Equilibr. 300 (2011) 1-69.

[22] E. Carretier, Study of Hydrodynamics in the Precipitation Autoclaves Used for the Supercritical Anti-Solvent (SAS) Process, Ph. D. Thesis, Aix Marseille University, 2002.

[23] E. Carretier, E. Badens, P. Guichardon, O. Boutin, G. Charbit, Hydrodynamics of supercritical antisolvent precipitation: characterization and influence on particle morphology, Ind. Eng. Chem. Res. 42 (2003) 331-338.

[24] E. Badens, O. Boutin, G. Charbit, Laminar jet dispersion and jet atomization in pressurized carbon dioxide, J. Supercrit. Fluids 36 (2005) 81-90.

[25] T. Petit-Gas, O. Boutin, I. Raspo, E. Badens, Role of hydrodynamics in supercritical antisolvent processes, J. Supercrit. Fluids 51 (2009) 248-255.

[26] E. Reverchon, E. Torino, S. Dowy, A. Braeuer, A. Leipertz, Interactions of phase equilibria, jet fluid dynamics and mass transfer during supercritical antisolvent micronization, Chem. Eng. J. 156 (2010) 446-458.

[27] S. Abdelli, Crystallization by Supercritical Anti-solvent Process (SAS): Influence of Operating Conditions on Crystal Polymorphism, Ph. D. Thesis, Aix Marseille University, 2017.

[28] E. Reverchon, I. De Marco, Supercritical antisolvent precipitation of Cephalosporins, Powder Technol. 164 (2006) 139-146.

[29] C. Neurohr, A. Erriguible, S. Laugier, P. Subra-Paternault, Challenge of the supercritical antisolvent technique SAS to prepare cocrystal-pure powders of naproxennicotinamide, Chem. Eng. J. 303 (2016) 238-251.

[30] T. Fernández-Ponce, Y. Masmoudi, R. Djerafi, L. Casas, C. Mantell, E. Martínez de la Ossa, E. Badens, Particle design applied to quercetin using supercritical anti-solvent techniques, J. Supercrit. Fluids 105 (2015) 119-127.

[31] R. Djerafi, A. Swanpaul, P. Labuschagne, M.L. Kalombo, E. Badens, C. Crampon, Y. Masmoudi, Supercritical antisolvent co-precipitation of Rifampicin and Ethyl cellulose, Eur. J. Pharm. Sci. 102 (2017) 161-171.

[32] Q. Li, D. Huang, T. Lu, J.P.K. Seville, L. Xing, G.A. Leeke, Supercritical fluid coating of API on excipient enhances drug release, Chem. Eng. J. 313 (2017) 317-327.

[33] A. Tandya, H.Q. Zhuang, R. Mammucari, N.R. Foster, Supercritical fluid micronization techniques for gastroresistant insulin formulations, J. Supercrit. Fluids 107 (2016) 9-16.

[34] M. Tservitas, M.S. Levy, M.Y.A. Lo-Yim, R.D. O'Kennedy, P. York, G.O. Humphrey, M. Hoare, The formation of plasmid DNA loaded pharmaceutical powders using supercritical fluid technology, Biotech. Bioeng. 72 (2001) 12-18.

[35] V. Prosapio, E. Reverchon, I. de Marco, Antisolvent micronization of bovine serum albumin using supercritical mixtures carbon dioxide + organic solvents, $\mathrm{J}$ Supercrit. Fluids 94 (2014) 189-197.

[36] J. Jung, J.Y. Clavier, M. Perrut, Preparation of inhalable protein particles by SCF emulsion drying, in: G. Brunner, I. Kikic, M. Perrut (Eds.), Proceedings of the 6th International Symposium on Supercritical Fluids, Versailles (France), 2003, pp. 1837-1842.

[37] G. Della Porta, N. Falco, E. Giordano, E. Reverchon, PLGA microspheres by Supercritical Emulsion Extraction: a study on insulin release in myoblast culture, J. Biomater. Sci. Polym. Ed. 24 (2013) 1831-1847.

[38] E. Reverchon, R. Adami, S. Cardea, G. Della Porta, Supercritical fluid processing of polymers for pharmaceutical and medical applications, J. Supercrit. Fluids 47 (2009) 484-492.

[39] M.J. Whitaker, J. Ho, O.R. Davies, G. Serhatkulu, S. Stolnik-Trenkic, S.M. Howdle, K.M. Skakesheff, The production of protein loaded microparticles by supercritical fluid enhanced mixing and spraying, J. Controlled Release 101 (2005) 85-92.

[40] F. Jordan, A. Naylor, C.A. Kelly, S.M. Howdle, A.L. Lewis, L. Illum, Sustained release hGH microspheres formulation produced by a novel supercritical fluid technology: in vivo studies, J. Controlled Release 141 (2010) 153-160.

[41] C.A. Kelly, S.M. Howdle, A. Naylor, G. Coxhill, L.C. Tye, L. Illum, A.L. Lewis, Stability of human growth hormone in supercritical carbon dioxide, J. Pharm. Sci. 101 (2012) 56-67.

[42] D.R. Perinelli, G. Bonacucina, M. Cespi, A. Naylor, M. Whitaker, G.F. Palmieri, G. Giorgioni, L. Casettari, Evaluation of P(L)LA-PEG-P(L)LA as processing aid for biodegradable particles from gas saturated solutions (PGSS) process, Int. J. Pharmaceut. 468 (2014) 250-257.

[43] K. Vezzu, D. Borin, A. Bertucco, S. Bersani, S. Salmaso, P. Caliceti, Production of lipid microparticles containing bioactive molecules functionalized with PEG, J. Supercrit. Fluids 54 (2010) 328-334.

44] A.S. Pedro, S. Dalla Villa, P. Caliceti, S.A.B. Vieira de Melo, E.C. Albuquerque, A. Bertucco, S. Salmaso, Curcumin-loaded solid lipid particles by PGSS technology, J. Supercrit. Fluids 107 (2016) 534-541.

[45] R. Couto, V. Alvarez, F. Temelli, Encapsulation of Vitamin B2 in solid lipid nanoparticles using supercritical $\mathrm{CO}_{2}$, J. Supercrit. Fluids 120 (2017) 432-442.

[46] M. Pemsel, S. Schwab, A. Scheurer, D. Freitag, R. Schatz, E. Schlucker, Advanced PGSS process for the encapsulation of the biopesticide Cydia pomonella granulovirus, J. Supercrit. Fluids 53 (2010) 174-178.

47] M. Thantsha, T.E. Cloete, F.S. Moolman, P.W. Labuschagne, Supercritical carbon dioxide interpolymer complexes improve survival of B. longum Bb-46 in simulated gastrointestinal fluids, Int. J. Food Microbiol. 129 (2009) 88-92.

[48] M. Chauvet, M. Sauceau, J. Fages, Extrusion assisted by supercritical $\mathrm{CO}_{2}$ : A review on its application to biopolymers, J. Supercrit. Fluids 120 (2017) 408-420.

[49] T. Clifford, Fundamentals of Supercritical Fluids, Oxford Science Publications, 1999 ISBN-13: 978-0198501374, ISBN-10:0198501374.

[50] X.Q. Bian, Q. Zhang, Z.M. Du, J. Chen, J.N. Jaubert, A five-parameter empirical model for correlating the solubility of solid compounds in supercritical carbon dioxide, Fluid Phase Equilibr. 11 (2016) 74-80.

[51] Y. Sato, K. Fujiwara, T. Takikawa, S. Takishima, H. Masuoka, Solubilities and dif fusion coefficients of carbon dioxide and nitrogen in polypropylene, high-density polyethylene, and polystyrene under high pressures and temperatures, Fluid Phase Equilibr. 162 (1999) 261-276.

[52] J. Hao, M.J. Whitaker, B. Wong, G. Serhatkulu, K.M. Shakesheff, S.M. Howdle, Plasticization and spraying of poly(DL-lactic acid) using supercritical carbon dioxide: control of particle size, J. Pharm. Sci. 93 (2004) 1083-1090.

53] T. Shinkai, K. Ito, H. Yokoyama, Swelling measurement of polymers in high pressure carbon dioxide using a spectroscopic reflectometer, J. Supercrit. Fluids 95 (2014) 553-559.

54] C. Gutiérrez, J.F. Rodríguez, I. Gracia, A. de Lucas, M.T. García, Modification of polystyrene properties by $\mathrm{CO}_{2}$ : Experimental study and correlation, J. Appl. Polym. Sci. 132 (2015) 41696-41704.

[55] I. Tsivintzelis, G. Sanxaridou, E. Pavlidou, C. Panayiotou, Foaming of polymers with supercritical fluids: a thermodynamic investigation, J. Supercrit. Fluids 110 (2016) 240-250.

[56] A. Braeuer, S. Dowy, E. Torino, M. Rossmann, S.K. Luther, E. Schluecker, A. Leipertz, E. Reverchon, Analysis of the supercritical antisolvent mechanisms governing particle precipitation and morphology by in situ laser scattering techniques, Chem. Eng. J. 173 (2011) 258-266.

[57] S. Dowy, E. Torino, S.K. Luther, M. Rossmann, A. Braeuer, Imaging the supersaturation in high-pressure systems for particle generation, Chem. Eng. J. 168 (2011) 896-902.

[58] P.W. Labuschagne, S.G. Kazarian, R.E. Sadiku, In situ FTIR spectroscopic study of the effect of $\mathrm{CO}_{2}$ sorption on H-bonding in PEG-PVP mixtures, Spectrochim. Acta A 78 (2011) 1500-1506.

[59] M. Perrut, Sterilization and virus inactivation by supercritical fluids (a review), J. Supercrit. Fluids 66 (2012) 359-371.

[60] S. Marre, Y. Roig, C. Aymonier, Supercritical microfluidics: opportunities in flowthrough chemistry and materials science, J. Supercrit. Fluids 66 (2012) 251-264.

[61] A. Martin, M.J. Cocero, Numerical modeling of jet hydrodynamics mass transfer, and crystallization kinetics in the supercritical antisolvent (SAS), J. Supercrit. Fluids 32 (2004) 203-219.

[62] A. Erriguible, C. Neurohr, A.L. Revelli, S. Laugier, G. Fevotte, P. Subra-Paternault Cocrystallization induced by compressed $\mathrm{CO}_{2}$ as antisolvent: simulation of a batch process for the estimation of nucleation and growth parameters, J. Supercrit. Fluids 98 (2015) 194-203.

[63] F. Kurniawansyah, R. Mammucari, A. Tandya, N.R. Foster, Scale-up and economic evaluation of the atomized rapid injection solvent extraction process, J. Supercrit Fluids 127 (2017) 208-216. 